\title{
The need for long-term surveillance of recovery of psychiatric patients with somatic complaints
}

\author{
Marja Kokkonen ${ }^{1}$, Kari Salke ${ }^{1}$, Tarja Saharinen ${ }^{1}$, Kaisa Haatainen ${ }^{1}$, Heli Koivumaa-Honkanen ${ }^{1,2,3,4}$ \\ ${ }^{1}$ Department of Psychiatry, Kuopio University Hospital, Kuopio, Finland \\ ${ }^{2}$ University of Eastern Finland, Kuopio University Hospital, Kuopio, Finland \\ ${ }^{3}$ Department of Psychiatry, University of Oulu, Oulu, Finland \\ ${ }^{4}$ Department of Psychiatry, Lapland Hospital District, Rovaniemi, Finland \\ Email: marja.kokkonen@kuh.fi
}

Received 12 February 2012; revised 15 March 2012; accepted 31 March 2012

\section{ABSTRACT}

Objective: Treatment of psychiatric patients with psychosomatic or somatic symptoms needs special attention. Methods: We examined correlates, change and recovery from depression among psychiatric patients $(n=150)$ during the assessment of their work ability. Patients were referred to an open psychiatric ward during 8/2004-9/2005. Psychiatric diseases were diagnosed with the ICD-10 by the psychiatrist, but also the Structured Clinical Interview for DSM-IV (SCID I and II) was conducted. The patients replied to questionnaires after admission and before discharge including questions on life changes, somatic health, psychosocial and health-related factors as well as psychometric scales for depression (BDI), life satisfaction (LS) and general psychopathology (SCL). RESULTS. At baseline, $75 \%$ of the patients reported clinically significant depression (BDI $>15)$ and a quarter of them experienced their depression as severe (BDI $\geq 30$ ). Whereas, according to ICD-10 guidelines, $91 \%$ of the patients suffered from depressive disorder and $66 \%$ of them from major depression. The average duration of inpatient evaluation was 24 (SD 9, 4) days. Baseline poor general health, life dissatisfaction, psychosomatic symptoms, bodily pains as well as poor financial situation and adverse life events predicted prevailing depression at discharge. Clinical symptoms improved significantly, especially among younger patients, recovery could not be reached by the time of discharge. Conclusions: Psychiatric patients with somatic complaints tended to under-rate their depression. To enhance their recovery, longterm and individually planned out-patient treatment and surveillance are needed.

Keywords: Depression; BDI; Somatic Symptoms; Life Satisfaction; Life Events

\section{INTRODUCTION}

Mood disorders and anxiety are linked with various physical illnesses [1]. Depression changes the homeostasis of the human body and predispose to [2] or strongly associates with several diseases such as coronary heart disease [3], type 2 diabetes [4-6] and metabolic syndrome [7]. One of the most common ailments of depressive patient in primary care is bodily pain. This association is bi-directional [8,9]. Also somatisation, distress [10] and anxiety have a role in pain complaints [11], but depression has been shown to be the most detrimental to quality of life, ability to function [12] and overall health among chronic physical diseases [13]. In patients with lumbar spinal stenosis, those with the comorbid depression [14] had the worst level of postoperative pain [15].

In general, vulnerability to depressiveness has been associated with somatic disease and stressful life events [16]. Also longitudinally, current physical health predicts depressive symptoms [17]. Patients with chronic somatic illnesses comorbid with depression were found to report more somatic complaints than those with only chronic somatic illnesses or depression alone [18]. On the other hand, primary care patients with depression and anxiety have a tendency to present first somatic symptoms [19].

Previously, it has been shown that severity of physical symptoms plays a role especially among psychiatric in-patients with personality disorders [20]. Their depression decreased during the hospital treatment if physical symptoms were only slight, but increased if they had severe physical symptoms or diseases. However, among unspecified psychiatric outpatients the alleviation of depression was not significantly associated with somatic comorbidity [21]. Thus, longitudinal studies focusing on patients with somatic and psychiatric comorbidities or psychosomatic problems are needed. These should include also investigation of the effect and role of hospital assessment of work ability among those with severe and long-term self-reported symptoms. This might help in the 
development and enhancement of their overall recovery as well as the planning of their subsequent outpatient treatment and rehabilitation.

In the present study, we investigated correlates and course of depression among adult psychosomatically or somatically ill psychiatric patients referred to a liaisonpsychiatric ward in a general hospital to assess their work ability and to formulate a rehabilitation plan.

\section{MATERIALS AND METHODS}

\subsection{Subjects and Data Collection}

This study, with data collection between August 2004 and September 2005, consisted of 150 successive patients (62 men and 88 women) referred to a work ability assessment and rehabilitation plan formulation due to psychiatric problems in an open liaison-psychiatric ward at Kuopio University Hospital. All the patients had also diagnosed somatic symptoms or diseases according to the referring physician. Four patients dropped out of the study. The treatment of three patients was premature disclosed due to their alcohol abuse and one patient did not answer the questionnaire at discharge. Thus, the study sample $(\mathrm{n}=146)$ consisted of 98 inpatients, 33 day clinic patients and 15 patients who were first inpatients, but continued as day clinic patients in the same ward. The average stay in the ward was 24 (SD 9.4) days. The data were collected with questionnaires after admission and before discharge.

Approval for the study was obtained from the Ethics Committee of Kuopio University Hospital. All patients gave their written informed consent before entering the study. Participation in this study did not affect the process of their work ability assessment, their regular treatment including appointments with a psychiatrist, personal therapy with a psychiatric nurse and group meetings (e.g. group discussion, music therapy group, occupational therapy group). Psychological tests, occupational therapy, counseling with a social worker and sessions with family members were used when needed. During the hospital treatment 135 patients accepted to receive psychotropic medication.

\subsection{Background Factors, Health Condition and Life Events}

All subjects completed a health questionnaire including questions on background factors (age, marital status, education, profession, financial situation), lifestyle (smoking, use of alcohol, physical activity and body mass index), self-rated health (good, fairly good or moderate vs fairly poor or poor), bodily pains or symptoms (none or slight vs moderate or severe) and a duration of bodily pains. Life events were assessed with 15 questions in- cluding 12 stressful and 3 positive life events ("no or only with minor meaning" vs "yes with quite or extremely significant meaning") [16]. A total sum of all life events was calculated. During the hospital treatment, somatic disorders were verified by the nurses from the patients' case history.

\subsection{Beck Depression Inventory (BDI)}

The level of depression was measured with the widelyused self-rated 21-item Beck Depression Inventory (BDI, range: 0 - 63) [22]. As a cut-off point for significant depression $14 / 15$ was used, since scores $\geq 15$ have been previously suggested to be relevant in screening for major depression [23].

\subsection{Life Satisfaction (LS) and Psychosomatic Symptoms (SCL)}

Life satisfaction (LS) was assessed by using the selfrated 4-item scale (range 4 - 20) [24]. The cut-off point for satisfaction was set at $11 / 12$, with scores $\geq 12$ indicating life dissatisfaction [25]. It has been successfully used both in general as well as patients population for measuring subjective well-being and predicting severe health outcomes [24-28]. Also the self-rated 12-item subscale of the SCL-90 for somatization (mean range: 1 5) [29] was used.

\subsection{Psychiatric Diagnosis}

Psychiatric diseases were diagnosed with the ICD-10 (Classification of Diseases and Related Health Problems 1992) [30] by the treating psychiatrist. The Structured Clinical Interview for DSM-IV, 1994 (SCID I and II) [31, 32] was conducted during the hospital treatment by trained psychiatric nurses or a social worker.

\subsection{Data Analysis and Statistical Methods}

Analyses were performed with SPSS 14.0 for Windows. The data distribution was tested against normality using the Kolmogorov-Smirnov test. The statistical significance of differences was examined Pearson's chi-squared and Fisher's exact test for categorical variables. The paired $t$ test for dependent samples was used to determine the statistical significance of changes, and in the case of non-normally distributed variable Wilcoxon's test. The $t$ test for independent samples or Mann-Whitney U-test (non-normally distribution) was used for the examination of differences between means of continuous variables. Multivariate logistic regression analyses (method enter) were used to assess the factors significantly associated with depression (BDI $\geq 15$ ) at discharge. Model 1 (method enter) included the significant factors associated with depression at discharge (i.e. age, LS, 
SCL, duration of bodily pains and financial situation). All the significant correlates of recovery (age, self-rated health, duration of bodily pains) were first adjusted with LS and SCL in a logistic model (method enter) in respect to at least partial recovery. Then, in the model 2 (method enter) only age was included with LS and SCL, since it was the only significant predictor. Pearson's correlation coefficients were used to assess the correlation between explanatory variables. The level of statistical significance was $\mathrm{p}<0.05$ in all analyses.

\section{RESULTS}

\subsection{Background Characteristics}

The mean age of all the patients was 48.4 years (SD 7.8).
They were usually married or cohabiting, white-collar workers, in a poor financial situation and were on sick leave, which had already lasted an average of 14 months. General health tended to be poor, the patients suffered from at least moderate bodily pains and symptoms that had lasted often over 2 years. Only a quarter $(27 \%)$ of the patients experienced their depression as severe at admission. The men were more often blue collar-workers (i.e. without a higher education), frequent alcohol users and less satisfied with their life (LS) than the women, whereas the women had more bodily pains than the men (Table 1). As meaningful life events, the patients reported illness causing work disability (83\%), the death of a close relative $(75 \%)$ and a poor financial situation (64\%). The women had experienced marital difficulties

Table 1. Background characteristics of psychosomatically or somatically ill adult psychiatric patients referred to the psychiatric ward of a general hospital.

\begin{tabular}{|c|c|c|c|c|c|}
\hline \multirow{2}{*}{ Variables, on admission } & $\begin{array}{c}\text { Men } \\
n=60\end{array}$ & $\begin{array}{l}\text { Women } \\
\mathrm{n}=86\end{array}$ & \multirow{2}{*}{ Test-statistics } & \multirow{2}{*}{ df } & \multirow{2}{*}{ P-value } \\
\hline & $\%$ & $\%$ & & & \\
\hline Married or cohabiting & 55 & 63 & $0.89^{1)}$ & 1 & ns \\
\hline Basic education & 80 & 83 & $0.15^{1)}$ & 1 & ns \\
\hline On sick leave or disabled & 70 & 80 & $2.03^{1)}$ & 1 & ns \\
\hline Financial situation: poor or fairy poor & 77 & 64 & $2.92^{1)}$ & 1 & ns \\
\hline Use of alcohol: $\geq 2$ times per week & 20 & 8 & $4.39^{1)}$ & 1 & 0.04 \\
\hline Current smoking & 35 & 22 & $2.96^{1)}$ & 1 & ns \\
\hline Overweight: $\mathrm{BMI} \geq 30$ & 33 & 40 & $0.58^{1)}$ & 1 & ns \\
\hline General health: fairly poor or poor & 67 & 74 & $1.04^{1)}$ & 1 & ns \\
\hline Bodily pain: moderate or severe & 77 & 87 & $1.12^{1)}$ & 1 & $\mathrm{~ns}$ \\
\hline \multicolumn{6}{|l|}{ Life events } \\
\hline Death of a close relative or friend & 68 & 79 & $2.09^{1)}$ & 1 & $\mathrm{~ns}$ \\
\hline Changes in health of a family member & 45 & 62 & $4.17^{1)}$ & 1 & 0.04 \\
\hline Lost of the job & 55 & 35 & $6.27^{1)}$ & 1 & 0.01 \\
\hline Increased marital difficulties & 20 & 40 & $6.19^{1)}$ & 1 & 0.01 \\
\hline Age (years/mean, SD) & $49.1(6.5)$ & $48.0(8.7)$ & $2.26^{2)}$ & 144 & ns \\
\hline LS (mean, SD) & $15.4(3.7)$ & $14.2(3.4)$ & $2.01^{2)}$ & & 0.02 \\
\hline $\mathrm{SCL}^{3)}$ (mean, $\left.\mathrm{SD}\right)$ & $2.7(0.8)$ & $3.0(0.8)$ & $0.19^{2)}$ & 139 & ns \\
\hline BDI (mean, SD) & $24.0(11.4)$ & $24.4(10.5)$ & $0.90^{2)}$ & 138 & $\mathrm{~ns}$ \\
\hline
\end{tabular}

Variables c.f. method section, ${ }^{1)} \chi^{2}$-value; ${ }^{2)} \mathrm{F}$-value; ${ }^{3)}$ psychosomatic subscale. 
and anxiety about the health of a family member more often than the men, and correspondingly, the men had lost their job more often than the women (Table 1).

\subsection{Changes in Psychometric Scales during Hospital Evaluation}

A positive and statistically significant improvement took place during the hospital assessment period in respect to BDI, LS and SCL scores (Table 2), bodily pains and self-rated health, but the clinical recovery was only started. At the admission, $75 \%$ of the patients had suffered from clinically significant depression (BDI $\geq 15$ ), and $27 \%$ of them had had severe depressiveness (BDI $\geq$ 30 ), while the corresponding figures at discharge were $65 \%$ and $20 \%$, respectively. Life dissatisfaction was very common ( $80 \%$ of the patients) on admission and still at discharge (75\%). Corresponding figures concerning bodily pains were $83 \%$ and $71 \%$. Also self-rated health was poor even if slightly better $(71 \%)$ at the admission than at the discharge $(73 \%)$.

\subsection{Diseases and Complaints at Discharge}

Both psychiatric and somatic diseases were diagnosed among $84 \%(\mathrm{n}=122)$ of the study subjects at discharge. Out of these, $49 \%$ had musculoskeletal diseases. Depression (ICD-10) was diagnosed among 91\% $(\mathrm{n}=133)$ of the patients (major depression $66 \%, \mathrm{n}=96$ ) and personality disorder among $77 \%(\mathrm{n}=112)$ of the patients (obsessive-compulsive personality $27 \%, \mathrm{n}=40$ ). According to the SCID I and II-interviews these figures were $71 \%$ $(\mathrm{n}=103)$ for major depression and $30 \%(\mathrm{n}=44)$ for personality disorder (obsessive-compulsive personality $16 \%, \mathrm{n}=24)$. Only $15 \%$ of the patients reported that they had not previously needed any psychiatric treatment.

\subsection{Baseline Factors Associated with Depression at Discharge}

Baseline life satisfaction ( $L S \geq 12$ ) in all the study subjects $\left(\chi^{2}=13.56, \mathrm{df}=1, \mathrm{P}<0.001\right)$ and the mean baseline SCL psychosomatic subscale score in the women $(\mathrm{F}$ $=1.77, \mathrm{df}=103, \mathrm{P}=0.001)$ were strongly associated with depression $(\mathrm{BDI} \geq 15)$ at discharge. This was true also for bodily pains $\left(\chi^{2}=8.71\right.$, $\left.\mathrm{df}=1, \mathrm{P}=0.003\right)$, self-rated health $\left(\chi^{2}=21.58, \mathrm{df}=1, \mathrm{P}<0.001\right)$ and financial situation $\left(\chi^{2}=4.53, \mathrm{df}=1, \mathrm{P}=0.03\right)$ at baseline.

When life events were examined, the death of a close relative $\left(\chi^{2}=5.96, \mathrm{df}=1, \mathrm{P}=0.02\right)$, considerable financial difficulties $\left(\chi^{2}=9.31, \mathrm{df}=1, \mathrm{P}=0.002\right)$, the breaking of a long-term relationship $\left(\chi^{2}=4.24, \mathrm{df}=1, \mathrm{P}=\right.$ $0.04)$ and loss of a job $\left(\chi^{2}=4.61, \mathrm{df}=1, \mathrm{P}=0.03\right)$ were associated with depression (BDI $\geq 15)$ at discharge in the women. On the other hand, a positive change in their relationships $\left(\chi^{2}=4.49, \mathrm{df}=1, \mathrm{P}=0.03\right)$ was beneficial with respect to the depression status at discharge. In the men, depression was statically significantly associated only with sexual difficulties $\left(\chi^{2}=5.24, \mathrm{df}=1, \mathrm{P}=0.02\right)$ when separate life events were studied.

The clinical factors that were significantly associated with depression (BDI $\geq 15)$ at discharge among all subjects were tested with logistic analyses (Table $\mathbf{3}$, model 1). Higher baseline life dissatisfaction (LS) and psychosomatic symptoms (SCL), duration of bodily pains of over one year and a poor financial situation on admission increased the risk of depression (BDI $\geq 15)$ at discharge.

\subsection{Baseline Factors Associated with Recovery from Depression at Discharge}

When at least partial recovery was measured as having BDI score $\geq 15$ on admission and BDI $<15$ at discharge, those fulfilling these criteria $(\mathrm{n}=19)$ were younger (mean 44.0, SD 10.6; $\mathrm{F}=3.77, \mathrm{df}=107 ; \mathrm{P}=0.02$ ), had better self-rated health $\left(\chi^{2}=6.10, \mathrm{df}=1, \mathrm{P}=0.03\right)$ and suffered fewer bodily pains $\left(\chi^{2}=5.25, \mathrm{df}=1, \mathrm{P}=0.03\right)$ on admission than those without recovery (BDI $\geq 15$ ). Life satisfaction (LS), psychosomatic symptoms (SCL), life events and other background characteristics had no statistically significant association with recovery measured like this. However, age was significantly associated with at least partial recovery after adjusting for LS and SCL (Table 3, model 2).

\section{DISCUSSION}

The severe depression of the patients with somatic complaints needs long-term out-patient surveillance after

Table 2. Mean scores for psychometric scales on admission and at discharge among psychosomatically or somatically ill adult psychiatric patients referred to the psychiatric ward of a general hospital.

\begin{tabular}{ccccccc}
\hline Variables & $\mathrm{n}$ & $\begin{array}{c}\text { Admission } \\
\text { Mean, SD }\end{array}$ & $\begin{array}{l}\text { Discharge } \\
\text { Mean, SD }\end{array}$ & Test-statistics & df & P-value \\
\hline BDI score & 131 & $24.2(11.0)$ & $21.6(11.3)$ & 3.55 & 130 & 0.001 \\
LS score & 145 & $14.7(3.6)$ & $13.7(3.7)$ & 1.97 & 0.000 \\
SCL-90, subscale & 137 & $2.9(0.8)$ & $2.7(0.8)$ & 5.96 & 136 & 0.000 \\
\hline
\end{tabular}

BDI = Beck Depression Inventory; LS = Life Satisfaction Scale; SCL-90, subscale = psychosomatic subscale of SCL-90, Symptom Check List including 12 items. 
Table 3. The adjusted odds ratios (OR) with $95 \%$ confidence intervals $(\mathrm{CI})$ related to depression (BDI $\geq 15)($ Model 1$)$ and at least partial recovery ${ }^{\mathrm{a})}(\text { Model } 2)^{*}$.

\begin{tabular}{|c|c|c|c|c|}
\hline \multirow{2}{*}{ Variables on admission } & \multicolumn{4}{|c|}{$95 \% \mathrm{CI}$} \\
\hline & OR & Lower & Upper & P-value \\
\hline \multicolumn{5}{|c|}{ Model 1: Depression at discharge } \\
\hline Age & 1.02 & 0.96 & 1.09 & ns. \\
\hline $\mathrm{LS}^{\mathrm{b})}$ & 1.29 & 1.13 & 1.48 & 0.001 \\
\hline $\mathrm{SCL}^{\mathrm{c})}$ & 2.74 & 1.47 & 5.11 & 0.002 \\
\hline Bodily pain ${ }^{\mathrm{d})}$ & 0.19 & 0.03 & 0.96 & 0.05 \\
\hline Financial situation & 2.68 & 1.02 & 7.04 & 0.05 \\
\hline \multicolumn{5}{|c|}{ Model 2: Partial recovery at discharge } \\
\hline Age & 0.94 & 0.88 & 0.99 & 0.03 \\
\hline LS & 0.87 & 0.73 & 1.04 & ns. \\
\hline SCL & 0.57 & 0.28 & 1.17 & ns. \\
\hline
\end{tabular}

${ }^{*}$ Logistic models 1 - 2: all the factors together in the model (method enter); ${ }^{\text {a) }}$ At least partial recovery $=$ at baseline BDI $\geq 15$ and at discharge BDI $<15$; ${ }^{\text {b) }}$ LS $=$ Life Satisfaction Scale (range $4-20$, continuous variable); ${ }^{\text {c) }} \mathrm{SCL}=$ Symptom Check List (range $0-4$, continuous variable); ${ }^{\text {d) }}$ Duration of bodily pain $=$ less than one year vs one year or longer; ${ }^{\mathrm{e})}$ Financial situation $=$ good vs poor.

assessment of their clinical status and work ability. Poor subjective health, long-lasting bodily pains, psychosomatic symptoms and life dissatisfaction at referral predicted depression at discharge, regardless of gender. They improved during the work ability assessment, but recovery was only started at the time of discharge.

Only $13 \%$ of the patients recovered at least partially from severe depression during their hospital stay. This is not surprising, since the recovery process is time-taking in depression, and can be more difficult if somatic complaints are involved. A younger age was beneficial for recovery paralleling to a study on partial recovery from major depression among outpatients of the same area of Finland [33]. Many of the patients of the present study had been in poor health for several years, but reported having been left without care. Thus, the special nature of psychosomatic problems is challenging. Better care of both somatic and mental health after evaluation period as well as long-lasting support should be provided if needed [12,27].

A poor health status, bodily pains and psychosomatic symptoms were linked with depressive symptoms. The study subjects reported long-lasting physical pains paralleling to the study of Alvarenga et al. [8] of patients with MDD and pain. Indeed, depression complicates the treatment of patients with pain, and vice versa $[12,17]$. Pains, chronic physical illnesses and psychosomatic symptoms may complicate the recognition of the psychological problems of the patients. Depression may remain unnoticed. Also the dualistic tendency especially of liaison-psychiatric patients to keep the body and mind separate may increase the risk of dropping out from psychiatric treatment. This risk should be minimized to avoid seeking repeatedly new health authorities after rejections by previous ones. Also the fear of the stigma of psychiatric disorders among these patients should be alleviated [34]. This might enhance the recovery from depression and restore the personal life satisfaction and self-respect of the patients. However, also comorbid personality disorder is a challenge for a good treatment outcome [35].

Life satisfaction has shown to be lowest among subjects with hospital discharge due to mental health disorders compared to other disorders [26]. It is strongly linked with various indicators of mental health [28], but especially with depression, even in longitudinal settings $[25,27]$. The proportion of dissatisfied (LS > 11) among the psychosomatically or somatically ill psychiatric patients of the present study $(80 \%)$ was far greater than that among overall non-healthy Finns (25\%). Thus, depression with somatic complaints seems to be especially hazardous to one's subjective well-being.

In spite of all this, the study subjects assessed their depression as being milder than the treating psychiatrist. Even though the majority of them reported clinically significant depression, only a quarter experienced their depression as severe, while according to the psychiatrist almost two-thirds of the patients suffered from major depressive disorder. This result contrasts with findings from other depression patients, but might be typical for psychosomatic patients, but it needs further research.

While several adverse life changes were correlates of 
depression in the women (i.e. financial difficulties, the loss of a job and breaking off of a long-term relationship) as in a previous study among the female general population from the same area [36] the only such correlate in the men was difficulties in their sexual life. How psychosomatic tendency or possible alexithymia in men might play role in this? This finding emphasizes, however, the assessment of sexual difficulties particularly among men with psychosomatic complaints.

The strength of the present study was the homogeneous and fairly large sample $(n=146)$. The results obtained may be generalized to depressive patients with chronic somatic symptoms seeking help from non-psychiatric specialists. In the present sample, the chronic psychiatric, somatic and psychosomatic problems were leading them towards permanent disability. Since the recovery process had only started among the sample during the inpatient evaluation, further follow-up studies in the out-patient setting are especially warranted.

\section{CONCLUSION}

The findings emphasized the need for long-term outpatient surveillance of rehabilitation of psychiatric patients with somatic and psychosomatic problems after evaluation of their clinical status and work ability. Both their somatic and psychiatric needs, and especially their underreported depression and their psychosocial distresses due the long course of their illness should be recognized.

\section{REFERENCES}

[1] Balon, R. (2006) Mood, anxiety and physical illness: Body and mind, or mind and body? Depression and Anxiety, 23, 377-387. doi:10.1002/da.20217

[2] Halaris, A. (2009) Comorbidity between depression and cardiovascular disease. International Angiology, 28, 9299.

[3] Frasure-Smith, N. and Lespérance, F. (2006) Recent evidence linking coronary heart disease and depression. The Canadian Journal of Psychiatry, 51, 730-737.

[4] Engum, A. (2007) The role of depression and anxiety in onset of diabetes in a large population-based study. Journal of Psychosomatic Research, 62, 31-38. doi:10.1016/j.jpsychores.2006.07.009

[5] Wilson, D. and Warise, L. (2008) Cytokines and their role in depression. Perspectives in Psychiatric Care, 44, 285-289. doi:10.1111/j.1744-6163.2008.00188.x

[6] Zhang, J., Ye, M., Huang, H., Li, L. and Yang, A. (2008) Depression of chronic medical inpatients in China. Archives of Psychiatric Nursing, 22, 39-49. doi:10.1016/j.apnu.2007.04.007

[7] Viinamäki, H., Heiskanen, T., Lehto, S., Niskanen, L., Koivumaa-Honkanen, H., Tolmunen, T., Honkalampi, K., Saharinen, T., Haatainen, K. and Hintikka, J. (2009) As- sociation of depressive symptoms and metabolic syndrome in men. Acta Psychiatrica Scandinavica, 120, 23-29. doi:10.1111/j.1600-0447.2008.01333.x

[8] Alvarenga, M.E., Caniato, R.N., Mauritz, A., Braun, A., Aljeesh, Y. and Braune, B. (2008) Health service utilization in patients with major depression and co-morbid pain. Psychiatry and Clinical Neurosciences, 63, 101-106. doi:10.1111/j.1440-1819.2008.01898.x

[9] Lewandowski, W. (2004) Psychological Factors in chronic pain: A worthwhile undertaking for nursing. Archives of Psychiatric Nursing, 18, 97-105. doi:10.1016/j.apnu.2004.03.005

[10] Pincus, T., Burton, A.K., Vogel, S. and Field, A. (2002) Systematic review of psychological factors as predictors of chronicity/disability in prospective cohorts of low back pain. Spine, 27, E109-E120. doi:10.1097/00007632-200203010-00017

[11] Mok, L.C. and Lee, I.F.-K. (2008) Anxiety, depression and pain intensity in patients with low back pain who are admitted to acute care hospitals. Journal of Clinical Nursing, 17, 1471-1480. doi:10.1111/j.1365-2702.2007.02037.x

[12] Bair, M.J., Robinson, R.L., Katon, W. and Kroenke, K. (2003) Depression and pain comorbidity. Archives of Internal Medicine, 163, 2433-2445. doi:10.1001/archinte.163.20.2433

[13] Moussavi, S., Chatterji, S., Verdes, E., Tandon, A., Patel, V. and Ustun, B. (2007) Depression, chronic diseases, and decrements in health: Results from the World Health Surveys. The Lancet, 370, 851-858. doi:10.1016/S0140-6736(07)61415-9

[14] Sinikallio, S., Aalto, T., Airaksinen, O., Herno, A., Kröger, H, Savolainen, S., Turunen, V. and Viinamäki, H. (2006) Depression and associated factors in patients with lumbar spinal stenosis. Disability \& Rehabilitation, 28, 415-422. doi:10.1080/09638280500192462

[15] Sinikallio, S., Aalto, T., Airaksinen, O., Herno, A., Kröger, H. and Viinamäki, H. (2009) Depressive burden in the preoperative and early recovery phase predicts poorer surgery outcome among lumbar spinal stenosis patients: A one-year prospective follow-up study. Spine, 34, 25732578. doi:10.1097/BRS.0b013e3181b317bd

[16] Romanov, K., Varjonen, J., Kaprio, J. and Koskenvuo, M. (2003) Life events and depressiveness - The effect of adjustment for psychosocial factors, somatic health and genetic liability. Acta Psychiatrica Scandinavica, 107, 25-33. doi:10.1034/j.1600-0447.2003.01419.x

[17] Aro, R., Nyberg, N., Absetz, P., Henriksson, M. and Lönnqvist, J. (2001) Depressive symptoms in middleaged women are more strongly associated with physical health and social support than socioeconomic factors. Nordic Journal of Psychiatry, 55, 191-198. doi:10.1080/08039480152036074

[18] Chong, J., Reinschmidt, K.M. and Moreno, F.A. (2010) Symptoms of depression in a Hispanic primary care population with and without chronic medical illnesses. The Primary Care Companion to the Journal of Clinical Psychiatry, 12, e1-e9.

[19] Escobar, J.I., Interian, A., Diaz-Martinez, A. and Gara, M. 
(2006) Idiopathic physical symptoms: A common manifestation of psychiatric disorders in primary care. The International Journal of Neuropsychiatric Medicine, 11, 201-210.

[20] Antikainen, R. and Hintikka, J. (1996) Somatic comorbidity in personality disorder inpatients. Effect on treatment outcome in a 3-year follow-up study. Nordic Journal of Psychiatry, 50, 469-476. doi:10.3109/08039489609082515

[21] Viinamäki, H., Hintikka, J., Haatainen, K., Antikainen, R., Honkalampi, K., Haatainen, K., Koivumaa-Honkanen, H., Saarinen, P. and Lehtonen, J. (2000) Effect of somatic comorbidity on alleviation of depressive symptoms. The Australian and New Zealand Journal of Psychiatry, 34, 755-761.

[22] Beck, A., Ward, C., Mendelson, M., Mock, J. and Erbaugh, J. (1961) An inventory for measuring depression. Archives of General Psychiatry, 4, 561-571. doi:10.1001/archpsyc.1961.01710120031004

[23] Viinamäki, H., Tanskanen, A., Honkalampi, K., Koivumaa-Honkanen, H., Haatainen, K., Kaustio, O. and Hintikka, J. (2004) Is the beck depression inventory suitable for screening major depression in different phases of the disease? Nordic Journal of Psychiatry, 58, 49-53. doi:10.1080/08039480310000798

[24] Allardt, E. (1973) About dimensions of welfare: Explanatory analysis of the comparative Scandinavian survey. Research Group of Comparative Sociology. Research Reports, University of Helsinki, Helsinki.

[25] Koivumaa-Honkanen, H., Honkanen, R., Viinamäki, H., Heikkilä, K., Kaprio, J. and Koskenvuo, M. (2000) Selfreported life satisfaction and 20-year mortality in healthy Finnish adults. American Journal of Epidemiology, 152, 983-991. doi:10.1093/aje/152.10.983

[26] Koivumaa-Honkanen, H. (1998) Life satisfaction as a health predictor. Kuopio University Printing Office, Kuopio.

[27] Koivumaa-Honkanen, H., Kaprio, J., Honkanen, R., Viinamäki, H. and Koskenvuo, M. (2004) Life satisfaction and depression in a 15-year follow-up. Social Psychiatry and Psychiatric Epidemiology, 39, 994-999. doi:10.1007/s00127-004-0833-6

[28] Koivumaa-Honkanen, H., Huovinen, T.K., Honkalampi, K., Antikainen, R., Hintikka, J., Haatainen, K. and Viinamäki, H. (2008) Mental health and well-being in a 6-year follow-up of patients with depression: Assessments of patients and clinicians. Social Psychiatry and Psychiatric Epidemiology, 43, 688-696. doi:10.1007/s00127-008-0353-x

[29] Derogatis, L.R. and Cleary, P.A. (1977) Confirmation of the dimensional structure of the SCL-90: Study in construct validation. Journal of Clinical Psychology, 33, 981-989. doi:10.1002/1097-4679(197710)33:4<981::AID-JCLP22 70330412>3.0.CO;2-0

[30] World Health Organization (1992) International statistical classification of diseases and related health problems (ICD-10). World Health Organization, Geneva.

[31] First, M.B., Spitzer, R.L., Gibbon, M. and Williams, J.B.W. (1997) User's guide for the structured clinical interview for DSM-IV Axis I disorders (SCID-I) - Clinician Version. American Psychiatric Press, Washington DC.

[32] First, M.B., Gibbon, M., Spitzer, R.L. and Williams, J.B.W. (1997) Structured clinical interview for DSM-IV Axis II personality disorders (SCID-II). American Psychiatric Press, Washington DC.

[33] Viinamäki, V., Hintikka, J., Tanskanen, A., Honkalampi, K., Antikainen, R., Koivumaa-Honkanen, H., Haatainen, K., Saarinen, P. and Lehtonen, J. (2002) Partial remission in major depression: A two-phase, 12-month prospective study. Nordic Journal of Psychiatry, 56, 33-37. doi:10.1080/08039480252803891

[34] Givens, J.L., Katz, I.R., Bellamy, S. and Holmes, W.C. (2007) Stigma and the acceptability of depression treatments among african americans and whites. Journal of General Internal Medicine, 22, 1292-1297. doi:10.1007/s11606-007-0276-3

[35] Viinamäki, H., Haatainen, K., Honkalampi, K., Tanskanen, A., Koivumaa-Honkanen, H., Antikainen, R., Valkonen-Korhonen, M. and Hintikka, J. (2006) Which factors are important predictors of non-recovery from major depression? A 2-year prospective observational study. Nordic Journal of Psychiatry, 60, 410-416. doi:10.1080/08039480600937801

[36] Honkalampi, K., Hintikka, J., Haatainen, K., KoivumaaHonkanen, H., Tanskanen, A. and Viinamäki, H. (2005) Adverse childhood experiences, stressful life events or demographic factors: Which are important in women's depression? A 2-year follow-up population study. Australian and New Zealand Journal of Psychiatry, 39, 627632. doi:10.1080/j.1440-1614.2005.01636.x 